
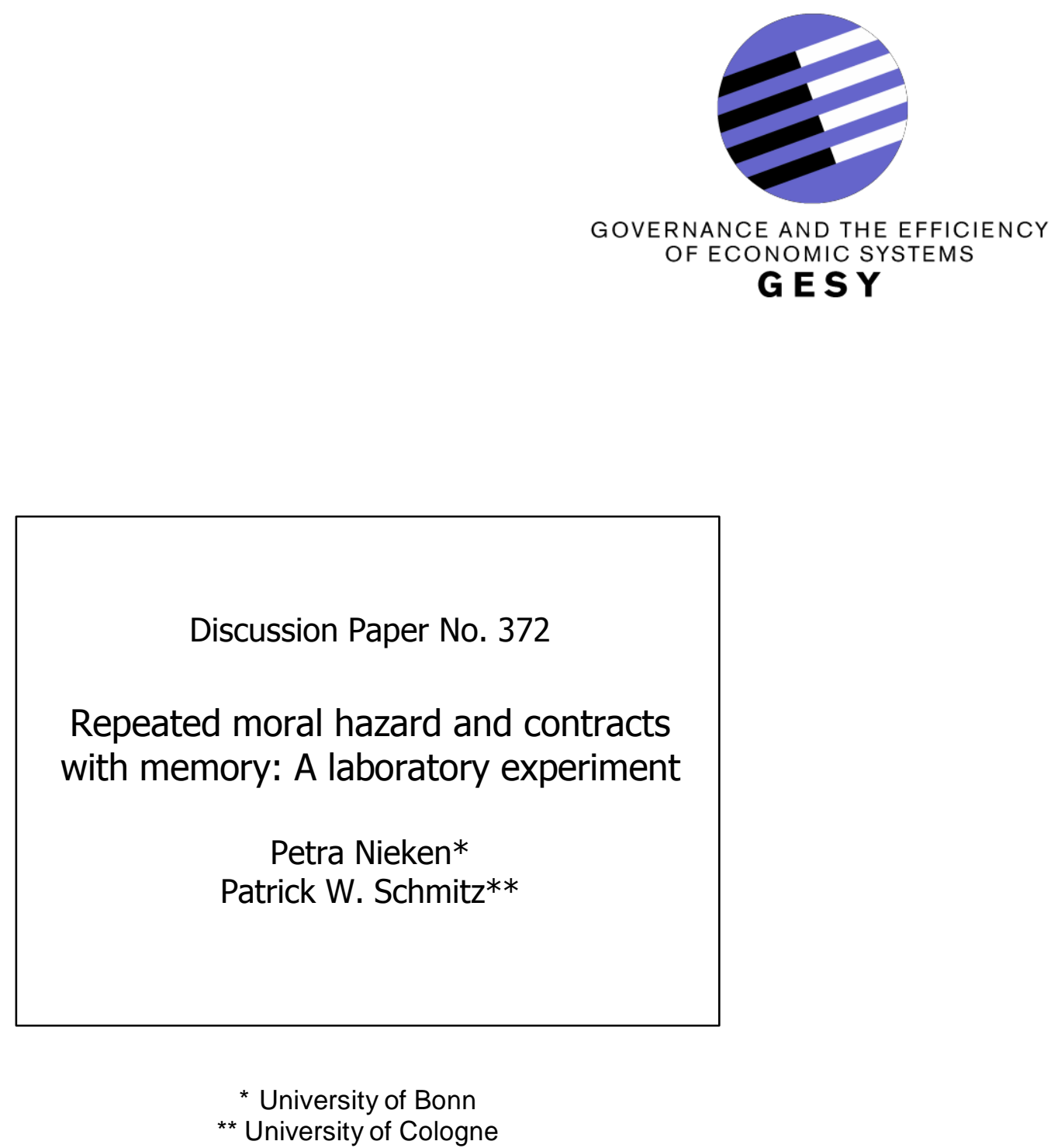

February 2012

Financial support from the Deutsche Forschungsgemeinschaft through SFB/TR 15 is gratefully acknowledged. 


\title{
Repeated moral hazard and contracts with memory: A laboratory experiment
}

\author{
Petra Nieken ${ }^{a, *}$, Patrick W. Schmitz ${ }^{b, c}$ \\ a University of Bonn, Department of Economics, Adenauerallee 24-42, \\ 53113 Bonn, Germany \\ ${ }^{b}$ University of Cologne, Department of Economics, Albertus-Magnus-Platz, \\ 50923 Köln, Germany \\ ${ }^{c}$ CEPR, London, UK
}

\begin{abstract}
This paper reports data from a laboratory experiment on twoperiod moral hazard problems. The findings corroborate the contract-theoretic insight that even though the periods are technologically unrelated, due to incentive considerations principals can benefit from offering long-term contracts that exhibit memory.
\end{abstract}

Keywords: Repeated moral hazard; Sequential hidden actions; Laboratory experiment

JEL classification codes: D82; J33

* Corresponding author. Tel.: +49228 73 9213; fax: +49 228739210.

E-mail address: petra.nieken@uni-bonn.de 


\section{Introduction}

This paper presents a laboratory experiment that investigates the role of long-term contracts with and without memory in a repeated hidden action framework. ${ }^{1}$ In a pioneering article, Rogerson (1985) analyzed a two-period moral hazard problem and showed that in an optimal long-term contract, the second-period incentives depend on the first-period outcome (i.e., the contract exhibits memory), even though the periods are technologically independent.

While Rogerson's result was driven by the consumption-smoothing motive of agents, ${ }^{2}$ similar findings can also be obtained in frameworks in which this motive is absent, so that memory in the optimal long-term contract is due to incentive considerations only. Specifically, consider the following problem.

There are two players, a principal and an agent. In period $i \in\{1,2\}$, the agent chooses an unobservable effort level $e_{i} \in\{0,1\}$. The agent's effort costs are given by $20 e_{i}$. If the agent chooses $e_{i}=1$, then the outcome of period $i$ will be a success. If the agent shirks (i.e., chooses $e_{i}=0$ ), then the outcome of period $i$ will be either a success or a failure, each with probability $1 / 2$. In case of a success, the principal's return in period $i$ is given by 70 , otherwise it is zero.

\begin{tabular}{|l|l|c|c|}
\hline $\begin{array}{c}\text { outcome } \\
\text { period } 1\end{array}$ & $\begin{array}{c}\text { outcome } \\
\text { period } 2\end{array}$ & $\begin{array}{c}\text { wage scheme } A \\
z_{A} \in\{25,30,35,40\}\end{array}$ & $\begin{array}{c}\text { wage scheme } B \\
z_{B} \in\{50,60,70,80\}\end{array}$ \\
\hline failure & failure & 0 & 0 \\
\hline success & failure & $z_{A}$ & 0 \\
\hline failure & success & $z_{A}$ & 0 \\
\hline success & success & $2 z_{A}$ & $z_{B}$ \\
\hline
\end{tabular}

Table 1. The principal can choose one of the four type- $A$ wage schemes (contracts without memory) or one of the four type- $B$ wage schemes (contracts with memory).

\footnotetext{
${ }^{1}$ For surveys on the theory of repeated moral hazard, see Bolton and Dewatripont (2005, ch. 10), Chiappori et al. (1994), and Laffont and Martimort (2002, ch. 8).

${ }^{2}$ Cf. Fudenberg, Holmström, and Milgrom (1990), Malcomson and Spinnewyn (1988), and Rey and Salanié (1990).
} 
Before the first period starts, the principal chooses one of the eight wage schemes shown in Table 1. There are two different types of wage schemes. According to a type- $A$ wage scheme, the agent gets a payment $z_{A}$ in each period in which there is a success and zero otherwise. Hence, type- $A$ wage schemes are contracts without memory. In contrast, in a type- $B$ wage scheme, the agent gets a payment $z_{B}$ if and only if both periods were successful, otherwise the payment is zero. Thus, type- $B$ wage schemes are contracts with memory.

The contract-theoretic analysis under standard assumptions (i.e., common knowledge of rationality, self-interested and risk-neutral preferences) is as follows. If the principal chooses a type- $A$ wage scheme, the agent will exert high effort in period $i$ whenever $z_{A}-20 \geq z_{A} / 2$. Hence, the agent is willing to choose high effort whenever the principal has set $z_{A} \geq 40$, otherwise the agent will shirk. ${ }^{3}$ The best admissible type- $A$ contract for the principal is thus $z_{A}=40$, leading to the profit $140-80=60 .{ }^{4}$ Now consider a type- $B$ wage scheme. The agent will shirk in the second period if the first period was a failure. Yet, if the first period was a success, the agent chooses high secondperiod effort whenever $z_{B}-20 \geq z_{B} / 2$, which is the case for all admissible values of $z_{B}$. The agent thus chooses high effort in the first period whenever $z_{B}-40 \geq\left(z_{B}-20\right) / 2$. Thus, the agent is willing to exert high effort in the first period if and only if the principal has set $z_{B} \geq 60$, otherwise the agent will shirk in the first period. The best type- $B$ contract for the principal is $z_{B}=60$, leading to the profit $140-60=80 .{ }^{5}$ Overall, the principal clearly prefers to offer the optimal contract with memory, $z_{B}=60$. Table 2 shows the agent's optimal effort levels and both players' expected profits for each wage scheme that the principal can offer.

\footnotetext{
${ }^{3}$ In contract theory it is usually assumed that an agent exerts high effort when the incentive compatibility constraint holds with equality. Note that if in the present context the agent were slightly risk averse, he would unambiguously prefer high effort when $z_{A}=40$.

${ }^{4}$ If the principal implemented low effort, she would set $z_{A}=25$ and her expected profit would be 45 only (note that she would prefer to implement low effort and make the expected profit 70 if a zero bonus were admissible).

${ }^{5}$ Indeed, if the principal implemented low effort in the first stage by setting $z_{B}=50$, her expected profit would be $(140-50) / 2+70 / 4=62.5$ only.
} 


\begin{tabular}{|c|c|c|c|c|c|}
\hline wage & optimal & optimal secor & -period effort & expe & ed profit \\
\hline scheme & first-period effort & first-period failure & first-period success & agent & principal \\
\hline$z_{A}=25$ & 0 & 0 & 0 & 25 & 45 \\
\hline$z_{A}=30$ & 0 & 0 & 0 & 30 & 40 \\
\hline$z_{A}=35$ & 0 & 0 & 0 & 35 & 35 \\
\hline$z_{A}=40$ & 1 & 1 & 1 & 40 & 60 \\
\hline$z_{B}=50$ & 0 & 0 & 1 & 15 & 62.5 \\
\hline$z_{B}=60$ & 1 & 1 & 1 & 20 & 80 \\
\hline$z_{B}=70$ & 1 & 1 & 1 & 30 & 70 \\
\hline$z_{B}=80$ & 1 & 1 & 1 & 40 & 60 \\
\hline
\end{tabular}

Table 2. Optimal effort levels and expected profits.

Guided by the contract-theoretic analysis, our predictions are as follows. (1a) Principals should make larger profits with a memory contract offering $z_{B}$ than with a no-memory contract offering $z_{A}=z_{B} / 2$, and (1b) hence they should prefer type- $B$ wage schemes. Moreover, (2a) principals should make the largest profit when $z_{B}=60$ and $(2 \mathrm{~b})$ hence prefer to offer this wage scheme. Furthermore, (3) given type- $A$ contracts, agents should exert considerably more effort (in both periods) when $z_{A}=40$ than when $z_{A}$ is smaller. Finally, given type- $B$ contracts, (4) agents should exert considerably less first-period effort when $z_{B}=50$ than when $z_{B}$ is larger, and (5) they should exert much more second-period effort following a first-period success than following a first-period failure.

Our example captures the main features of the more general framework investigated by Ohlendorf and Schmitz (2012). In particular, also when effort is a continuous variable, renegotiation cannot be ruled out, and the only restriction put on the admissible contract space is limited liability (cf. Innes, 1990; Pitchford, 1998), the principal's optimal contract typically exhibits memory, ${ }^{6}$ despite the fact that the periods are technologically unrelated. ${ }^{7}$

\footnotetext{
${ }^{6}$ In the present example, note that the optimal contract $\left(z_{B}=60\right)$ is renegotiationproof. After a first-period success the agent would not accept a wage cut, while after a first-period failure, the principal would not be willing to implement high effort.

${ }^{7}$ See Schmitz (2005) for the case in which the periods are technologically related.
} 


\section{The Experiment}

\section{$2.1 \quad$ Design}

We have tested the contract-theoretic predictions in an experiment which was conducted at the Cologne Laboratory of Economic Research. ${ }^{8}$ At the beginning of the experiment, the subjects were randomly assigned to the roles of principals (employers) and agents (employees). Each principal was randomly and anonymously matched with one agent. We implemented a one-shot design to prevent reputation effects and to ensure a large number of independent observations. Altogether 358 students of the University of Cologne participated in the 12 sessions of the experiment. Each session took about 45 minutes. At the end of the experiment the subjects answered a questionnaire containing open questions where they could explain their decisions as well as questions regarding risk attitudes and demographic details. We used the fictitious currency "taler," which were later converted into euro. On average, the subjects earned 9.15 euro.

\subsection{The main results}

Table 3 shows the behavior of the principals. In line with prediction (1a), pairwise comparisons of wage schemes $z_{A}$ with the corresponding wage schemes $z_{B}=2 z_{A}$ show that the principals make much larger profits when they offer type- $B$ contracts. The differences were statistically significant in three of the four comparisons. ${ }^{9}$

Note that if the principals trusted the agents to exert high effort, they should be indifferent between wage schemes $z_{A}$ and $z_{B}=2 z_{A}$. Indeed, choosing a type- $B$ wage scheme might even be interpreted as an unfriendly signal of distrust by the agent, which might lead him to punish the principal

\footnotetext{
${ }^{8}$ We used the online recruitment system by Greiner (2004) for the recruitment of the players. The experiment was programmed using the experimental software z-tree by Fischbacher (2007).

${ }^{9}$ The $p$-values are $p=0.054$ for a comparison of $z_{A}=30$ with $z_{B}=60, p=0.000$ for $z_{A}=35$ versus $z_{B}=70$, and $p=0.045$ for $z_{A}=40$ versus $z_{B}=80$, according to two-sided Mann-Whitney U tests.
} 
by exerting low effort, so that the principal's profit would be smaller with type- $B$ wage schemes. But the results show that in most cases, the standard contract-theoretic reasoning is corroborated by the data. Most principals prefer to give the agent stronger incentives by choosing a multi-period contract with memory, which lead to larger profits.

Altogether, $31 \%$ of the principals chose type- $A$ wage schemes, while $69 \%$ chose type- $B$ wage schemes. The choices were significantly different from a random selection ( $p=0.000$, two-sided binomial test). Hence, the data of our experiment support prediction (1b), stating that principals would select type- $B$ rather than type- $A$ contracts.

\begin{tabular}{|c|c|c|c|}
\hline wage scheme & absolute frequency & relative frequency & average profit \\
\hline$z_{A}=25$ & 15 & $8.38 \%$ & 51.00 \\
\hline$z_{A}=30$ & 12 & $6.70 \%$ & 56.67 \\
\hline$z_{A}=35$ & 16 & $8.94 \%$ & 37.19 \\
\hline$z_{A}=40$ & 13 & $7.26 \%$ & 46.15 \\
\hline$z_{B}=50$ & 36 & $20.11 \%$ & 65.56 \\
\hline$z_{B}=60$ & 22 & $12.29 \%$ & 71.82 \\
\hline$z_{B}=70$ & 40 & $22.35 \%$ & 68.25 \\
\hline$z_{B}=80$ & 25 & $13.97 \%$ & 56.40 \\
\hline
\end{tabular}

Table 3. Principal's choice of a wage scheme and the average profit of the principal.

The average profit of the principal was highest with 71.82 taler for the wage scheme $z_{B}=60$. The differences between the profits given $z_{B}=60$ and the profits given alternative wage schemes were statistically significant for five of the seven alternatives. ${ }^{10}$ The finding that principals made the largest profits if they selected $z_{B}=60$ is in line with prediction (2a). However, as can be seen in Table 3 , only $12.29 \%$ of the principals chose the wage scheme

\footnotetext{
${ }^{10}$ The $p$-values are $p=0.054$ for a comparison of $z_{B}=60$ with $z_{A}=30$, and $p=0.000$ for comparisons of $z_{B}=60$ with $z_{A}=35, z_{A}=40, z_{B}=70$, or $z_{B}=80$, according to two-sided Mann-Whitney U tests.
} 
$z_{B}=60$, which is the optimal contract according to standard theory. Hence, we do not find support for prediction $(2 \mathrm{~b})$. In fact, the modal contract was $z_{B}=70$.

Thus, while we find strong support for the contract-theoretic prediction that the wage scheme $z_{B}=60$ is the most profitable one, principals often made more generous offers, sacrificing a part of their profit. When at the end of the experiment the players could explain their decisions, many of the principals claimed that offering half of the return of two successful periods constitutes a fair offer. On the other hand, several principals made rather small wage offers, which seem to be simple decision errors. We come back to fairness preferences and decision errors in the following section.

\begin{tabular}{|l|c|c|c|c|c|c|c|c|c|}
\hline \multirow{2}{*}{$\begin{array}{l}\text { wage } \\
\text { scheme }\end{array}$} & \multicolumn{4}{|c|}{ first-period effort } & \multicolumn{5}{c|}{ second-period effort } \\
\cline { 2 - 11 } & \# obs. & \# high & average & \# obs. & \# high & average & \# obs. & \# high & average \\
\hline$z_{A}=25$ & 15 & 1 & 0.067 & 8 & 1 & 0.125 & 7 & 0 & 0 \\
\hline$z_{A}=30$ & 12 & 2 & 0.167 & 5 & 0 & 0 & 7 & 1 & 0.143 \\
\hline$z_{A}=35$ & 16 & 3 & 0.188 & 7 & 3 & 0.429 & 9 & 1 & 0.111 \\
\hline$z_{A}=40$ & 13 & 6 & 0.462 & 3 & 0 & 0 & 10 & 7 & 0.700 \\
\hline$z_{B}=50$ & 36 & 10 & 0.278 & 16 & 1 & 0.063 & 20 & 11 & 0.550 \\
\hline$z_{B}=60$ & 22 & 16 & 0.727 & 4 & 0 & 0 & 18 & 14 & 0.778 \\
\hline$z_{B}=70$ & 40 & 38 & 0.950 & 2 & 1 & 0.500 & 38 & 32 & 0.842 \\
\hline$z_{B}=80$ & 25 & 21 & 0.840 & 3 & 0 & 0 & 22 & 20 & 0.909 \\
\hline
\end{tabular}

Table 4. Average efforts of the agents for each period.

The reactions of the agents for given wage schemes are reported in Table 4. If the agent was confronted with a type- $A$ wage scheme, chosen effort (pooled over both periods) was significantly higher when $z_{A}=40$ than when $z_{A}$ was smaller. ${ }^{11}$ Hence, our findings are in favor of prediction (3). Given a

\footnotetext{
${ }^{11}$ The $p$-values are $0.001,0.006$, and 0.030 for a comparison of $z_{A}=40$ with $z_{A}=25$, $z_{A}=30$, and $z_{A}=35$, respectively, according to two-sided Fisher exact tests.
} 
type- $B$ wage scheme, the first-period effort level was significantly smaller for $z_{B}=50$ than when $z_{B}$ was larger. ${ }^{12}$ This is in line with prediction (4).

\begin{tabular}{lcccc}
\hline \hline & type-A wage schemes & \multicolumn{2}{c}{ type-B wage schemes } \\
& $(1)$ & $(2)$ & $(3)$ & $(4)$ \\
\hline dummy first period success & 0.219 & 0.200 & $2.146^{* * *}$ & $2.405^{* * *}$ \\
& $(0.403)$ & $(0.430)$ & $(0.403)$ & $(0.474)$ \\
age & & -0.003 & & 0.021 \\
& & $(0.102)$ & & $(0.034)$ \\
dummy female & & -0.613 & & 0.406 \\
& & $(0.486)$ & & $(0.298)$ \\
dummy field of study & & -0.179 & & 0.065 \\
& & $(0.502)$ & & $(0.332)$ \\
dummy participation & & -0.434 & & -0.365 \\
6 - 10 times & & $(0.527)$ & & $(0.370)$ \\
dummy participation & & -0.339 & & $0.817^{* *}$ \\
more than 10 times & & $(0.557)$ & & $(0.394)$ \\
\# of safe choices (H\&L) & & 0.140 & & -0.090 \\
& & $(0.121)$ & & $(0.093)$ \\
constant & $-0.842^{* * *}$ & -0.878 & $-1.335^{* * *}$ & $-1.966^{* *}$ \\
& $(0.319)$ & $(2.611)$ & $(0.375)$ & $(1.001)$ \\
\hline observations & 50 & 50 & 113 & 113 \\
(pseudo) $R^{2}$ & 0.0054 & 0.0650 & 0.2677 & 0.3611 \\
\hline
\end{tabular}

Standard errors in parentheses.

${ }^{* * *} \mathrm{p}<0.01,{ }^{* *} \mathrm{p}<0.05,{ }^{*} \mathrm{p}<0.1$

Table 5. Probit regression with second-period effort as dependent variable. The dummy variable "field of study" is 1 if the subjects were enrolled in economics or business administration, otherwise it is 0 . We measured risk aversion by implementing the ten paired lottery choice decisions from Holt and Laury (2002), the variable "\# of safe choices (H\&L)" indicating the number of safe choices of a subject in this lottery. We also controlled for the number of times subjects have participated in laboratory experiments before (variables "participation"), with 0 to 5 times as the reference category. ${ }^{13}$

${ }^{12}$ The $p$-values are $p=0.001$ for a comparison of $z_{B}=50$ with $z_{B}=60$, and $p=0.000$ for a comparison of $z_{B}=50$ with $z_{B}=70$ or $z_{B}=80$ (two-sided Fisher exact tests).

${ }^{13}$ For one session (16 subjects in the role of the agent) we have no information regarding demographics and risk attitude due to technical problems with the questionnaire. The results of specification (1) and (3) stay qualitativly the same if we include the 16 observations. 
As can be seen in Table 4, the average effort exerted in type- $B$ wage schemes depended on the outcome of the first period. Except for $z_{B}=70$, if the first period had been a success, the second-period effort was significantly higher than if the first period had been a failure. ${ }^{14}$ Probit regressions show that a success in the first period had a significant positive effect on secondperiod effort for type- $B$ wage schemes, but no significant effect for type- $A$ wage schemes (see Table 5). Hence, the agents' second-period effort was sensitive towards the outcome of the first period given type- $B$ wage schemes, which corroborates prediction (5). Note that demographic factors such as gender or age as well as the agents' attitude towards risk have no significant impact. Taken together, we find strong evidence for the fact that monetary incentives matter in the way predicted by contract theory.

\subsection{Social preferences and decision errors}

While the main contract-theoretic hypotheses with the exception of prediction $(2 \mathrm{~b})$ were corroborated by the data, there are several deviations from standard theory. First of all, in contrast to prediction (2b), the majority of the principals did not choose the wage scheme $z_{B}=60$, even though (as hypothesized in prediction 2 a) principals who chose this wage scheme made the largest profit. The modal wage scheme was $z_{B}=70$, so that when high effort is exerted in both periods, the principal offers the agent to pay him half of her returns. In the light of the vast experimental literature suggesting the relevance of fairness considerations (see Fehr and Schmidt, 2006), it is thus natural to examine the role of social preferences for the data.

Following Fehr and Schmidt's (1999) prominent model, let player $i$ 's utility be given by

$$
U_{i}\left(\pi_{i}, \pi_{j}\right)=\pi_{i}-\alpha_{i} \max \left\{\pi_{j}-\pi_{i}, 0\right\}-\beta_{i} \max \left\{\pi_{i}-\pi_{j}, 0\right\}, i \neq j
$$

where $\pi_{i}$ denotes player $i$ 's monetary payoff, $\alpha_{i}$ measures player $i$ 's disutility from disadvantageous inequality, and $\beta_{i}$ measures player $i$ 's disutility from

\footnotetext{
${ }^{14}$ The $p$-values are $p=0.004$ for $z_{B}=50, p=0.010$ for $z_{B}=60, p=0.004$ for $z_{B}=80$ (two-sided Fisher exact tests). Note that we have only two observations for a failure in the first period if $z_{B}=70$, where one agent selected $e_{2}=0$ and the other $e_{2}=1$.
} 
advantageous inequality. Fehr and Schmidt (1999) assume that $0 \leq \beta_{i}<1$ and $\alpha_{i} \geq \beta_{i}$.

Following the approach taken by Huck et al. (2011), we can characterize which decisions are Fehr-Schmidt rationalizable and which decisions cannot be explained by any values of $\alpha_{i}$ and $\beta_{i}$ (see Appendix A for details).

Specifically, given a memoryless contract $z_{A}$, effort in both periods must always be low if $z_{A} \in\{25,30,35\}$. Now consider $z_{A}=40$. In the second period, if there was a first-period success despite low first-period effort, then second-period effort will be high. Second-period effort in the other cases will be equal to first-period effort, which may be either low or high.

Given a memory contract $z_{B}$, first-period effort must be low if $z_{A}=50$, while it can be either low or high if $z_{B} \in\{60,70,80\}$. Given a first-period success, second-period effort can be either low or high if $z_{B}=50$, otherwise it must be high. Given a first-period failure, second-period effort must always be low.

Moreover, with regard to the principal's offer, the memoryless contracts $z_{A} \in\{35,40\}$ and the memory contracts $z_{B} \in\{50,60,70,80\}$ are FehrSchmidt rationalizable.

Hence, a wide array of behavior can be rationalized by the Fehr-Schmidt model. Nevertheless, there are still some deviations from standard theory in Tables 3 and 4 that cannot be explained by social preferences. In particular, $15 \%$ of the principals chose a memoryless contract with $z_{A} \leq 30$ (see Table 3). Moreover, as can be seen in Table 4, high effort was exerted in $14 \%$ of the cases when a memoryless contract with $z_{A} \leq 35$ was offered. Similarly, in $28 \%$ of the cases when a memory contract with $z_{B}=50$ was offered the agent exerted high effort in the first period.

To capture the fact that players make decision errors, we apply the wellknown quantal response equilibrium (QRE) framework that has been developed by McKelvey and Palfrey (1995). ${ }^{15}$ In particular, let $U_{i k}$ denote player $i$ 's expected utility if he makes a decision $k \in\{1, \ldots, n\}$. Then the probability

\footnotetext{
${ }^{15}$ Specifically, we use the agent quantal response equilibrium concept as described in McKelvey and Palfrey (1998), which takes the sequential structure of the game into account.
} 
that he chooses decision $k=\hat{k}$ is given by

$$
\frac{e^{\lambda U_{i \hat{k}}}}{\sum_{k=1}^{n} e^{\lambda U_{i k}}} .
$$

Thus, errors are less likely when they lead to larger utility losses. When computing his expected utility, the player takes into account that all decisions are made in this way. The parameter $\lambda$ can be interpreted as a rationality parameter. If $\lambda=0$, behavior is completely random, while behavior approaches rational choice if $\lambda$ becomes large. We use maximum likelihood to estimate the parameter $\lambda$. Following Rogers et al. (2009), we provide two benchmarks (see Table 6). The "random" log likelihood is a lower bound for the quality of fit; it results from a model where all decisions are randomly taken. The "empirical" log likelihood is the best possible fit to the aggregate data; it results from a model that assigns to each decision its empirical frequency.

As can be seen in the second row of Table 6, the standard QRE model in which utilities are equal to monetary payoffs leads to a fit that is substantially better than the lower bound. This observation is in line with the fact that most of the standard contract-theoretic predictions were borne out by the data. Yet, as can be seen in the third row, the fit can be further improved if we replace standard utility by Fehr-Schmidt utility. Since we estimate one Fehr-Schmidt utility function across all subjects, $\lambda$ now also captures the heterogeneity of preferences. ${ }^{16}$ It is interesting to note that only the Fehr-Schmidt parameter $\beta$ (which measures advantageous inequality) is significantly different from zero. Bellemare et al. (2008) have recently also found that the disutility from having more can be stronger than the disutility from having less (and the latter may even be negative, reflecting a preference for efficiency). ${ }^{17}$

\footnotetext{
${ }^{16}$ See also Blanco et al. (2011, section 6.1), De Bruyn and Bolton (2008), and Goeree and Holt (2000), who also use the QRE approach to estimate Fehr-Schmidt parameters.

${ }^{17}$ See also Blanco et al. (2011, section 4) for recent evidence contradicting Fehr and Schmidt's (1999) assumption that $\alpha \geq \beta$. In a related study, Dannenberg et al. (2007) have found that in their subject pool the median value of $\alpha$ is 0 , while the median value of $\beta$ is 0.375 .
} 


\begin{tabular}{|l|l|l|}
\hline random $\ln L$ & & $\ln L=-620.4$ \\
\hline QRE & $\lambda=0.080(0.009)$ & $\ln L=-568.8$ \\
\hline & $\lambda=0.136(0.014)$ & \\
FS-QRE & $\alpha=0.009(0.050)$ & $\ln L=-543.0$ \\
& $\beta=0.334(0.038)$ & \\
\hline empirical $\ln L$ & & $\ln L=-505.8$ \\
\hline
\end{tabular}

Table 6. Maximum likelihood estimations of the quantal response equilibrium model with standard preferences (QRE) and with Fehr-Schmidt preferences (FS-QRE). Standard errors are in parentheses.

\section{Concluding remarks}

We have found experimental support for the contract-theoretic insight that, due to incentive considerations, a principal can gain from offering long-term contracts exhibiting memory, even if the periods are technologically unrelated. While the agents qualitatively responded to the incentives as predicted by standard theory and the theoretically optimal contract yielded the largest profit, most principals did not pick this contract. The deviations from standard theory can be explained by decision errors and social preferences. Our structural estimation of a quantal response equilibrium model with FehrSchmidt preferences showed that in particular disutility from advantageous inequality seems to be relevant in our setting.

To our knowledge, Huck et al. (2011) is the only other experiment exploring the intertemporal allocation of wages. They test Lazear's (1979) theory of deferred compensation (i.e., wage profiles that are increasing over a worker's lifetime; cf. Akerlof and Katz, 1989; Lazear, 1981). While the models motivating the experiments are quite different, ${ }^{18}$ Huck et al. (2011) also find that agents respond strongly to monetary incentives and provide support for

\footnotetext{
${ }^{18}$ In the deferred compensation model, the principal can always deduce effort from output (so that with full commitment the first-best solution could be implemented with a Maskin mechanism; see Maskin, 1999; Maskin and Sjöström, 2002). Moreover, the wage in a given period does not depend on the output of that period, but the agent is dismissed with a certain probability after a period in which he exerted low effort.
} 
Lazear's idea that deferred compensation can be used to elicit effort. ${ }^{19}$

Taken together, in our view the recent findings of Huck et al. (2011) and the results reported in the present paper suggest that more experimental work on the incentive effects of long-term contracts guided by contract-theoretic research might be very promising.

\footnotetext{
${ }^{19}$ Yet, in their experiment only a sizable minority of principals actually decided to make no payment for the first period; which can be explained by social preferences and which might also be due to the fact that the principals' task was quite complex, as they had to set three wages.
} 


\section{Appendix A: Fehr-Schmidt preferences}

We now characterize the decisions that can be rationalized by Fehr-Schmidt utility functions.

Agent's behavior. Suppose the principal has offered a memoryless contract $z_{A}$. Given high first-period effort, agent $i$ 's second-period incentive compatibility constraint is $2 z_{A}-40-\alpha_{i} \max \left\{180-4 z_{A}, 0\right\}-\beta_{i} \max \left\{4 z_{A}-180,0\right\} \geq \frac{1}{2}\left(2 z_{A}-\right.$ $\left.20-\alpha_{i} \max \left\{160-4 z_{A}, 0\right\}-\beta_{i} \max \left\{4 z_{A}-160,0\right\}\right)+\frac{1}{2}\left(z_{A}-20-\alpha_{i} \max \{90-\right.$ $\left.\left.2 z_{A}, 0\right\}-\beta_{i} \max \left\{2 z_{A}-90,0\right\}\right)$. Hence, in the second period the agent chooses high effort if $z_{A}=40$ and $\alpha_{i}=0$, otherwise he chooses low effort.

Given low first-period effort and a first-period success, the agent's secondperiod incentive compatibility constraint is $2 z_{A}-20-\alpha_{i} \max \left\{160-4 z_{A}, 0\right\}-$ $\beta_{i} \max \left\{4 z_{A}-160,0\right\} \geq \frac{1}{2}\left(2 z_{A}-\alpha_{i} \max \left\{140-4 z_{A}, 0\right\}-\beta_{i} \max \left\{4 z_{A}-140,0\right\}\right)+$ $\frac{1}{2}\left(z_{A}-\alpha_{i} \max \left\{70-2 z_{A}, 0\right\}-\beta_{i} \max \left\{2 z_{A}-70,0\right\}\right)$. Thus, in the second period the agent always chooses high effort if $z_{A}=40$, and low effort otherwise.

Given low first-period effort and a first-period failure, the agent's secondperiod incentive compatibility constraint reads $z_{A}-20-\alpha_{i} \max \left\{90-2 z_{A}, 0\right\}-$ $\beta_{i} \max \left\{2 z_{A}-90,0\right\} \geq \frac{1}{2}\left(z_{A}-\alpha_{i} \max \left\{70-2 z_{A}, 0\right\}-\beta_{i} \max \left\{2 z_{A}-70,0\right\}\right)$. Hence, if $z_{A} \in\{25,30,35\}$ the agent chooses low effort in the second period, while in the case $z_{A}=40$ he chooses high effort if $5 \beta_{i}-10 \alpha_{i} \geq 0$ (which under the Fehr-Schmidt assumptions can happen only if $\alpha_{i}=0$ ).

Now consider the first period. If $z_{A}=40$ and $\alpha_{i}=0$, it is straightforward to check that the agent exerts high effort in the first period. If $z_{A}=40$ and $\alpha_{i}>0$, the first-period incentive compatibility constraint is $\frac{1}{2}\left(z_{A}-20-\right.$ $\left.\alpha_{i} \max \left\{90-2 z_{A}, 0\right\}-\beta_{i} \max \left\{2 z_{A}-90,0\right\}\right)+\frac{1}{2}\left(2 z_{A}-20-\alpha_{i} \max \left\{160-4 z_{A}, 0\right\}-\right.$ $\left.\beta_{i} \max \left\{4 z_{A}-160,0\right\}\right) \geq \frac{1}{4}\left(z_{A}-\alpha_{i} \max \left\{70-2 z_{A}, 0\right\}-\beta_{i} \max \left\{2 z_{A}-70,0\right\}\right)+$ $\frac{1}{2}\left(2 z_{A}-20-\alpha_{i} \max \left\{160-4 z_{A}, 0\right\}-\beta_{i} \max \left\{4 z_{A}-160,0\right\}\right)$, which implies that low effort is chosen in the first period. If $z_{A} \in\{25,30,35\}$, the righthand side of the first-period incentive compatibility constraint reads instead $\frac{1}{2}\left(z_{A}-\alpha_{i} \max \left\{70-2 z_{A}, 0\right\}-\beta_{i} \max \left\{2 z_{A}-70,0\right\}\right)+\frac{1}{4}\left(2 z_{A}-\alpha_{i} \max \{140-\right.$ $\left.\left.4 z_{A}, 0\right\}-\beta_{i} \max \left\{4 z_{A}-140,0\right\}\right)$, which again implies that the agent chooses low first-period effort.

Next, suppose the principal has offered a memory contract $z_{B}$. Given high first-period effort, agent $i$ 's second-period incentive compatibility constraint 
is $z_{B}-40-\alpha_{i} \max \left\{180-2 z_{B}, 0\right\}-\beta_{i} \max \left\{2 z_{B}-180,0\right\} \geq \frac{1}{2}\left(z_{B}-20-\right.$ $\left.\alpha_{i} \max \left\{160-2 z_{B}, 0\right\}-\beta_{i} \max \left\{2 z_{B}-160,0\right\}\right)+\frac{1}{2}\left(-20-90 \alpha_{i}\right)$. Hence, if $z_{B} \in\{60,70,80\}$, the agent always chooses high second-period effort. If $z_{B}=50$, he chooses high effort whenever $\alpha_{i} \leq 1$.

Given low first-period effort and a first-period success, the second-period incentive compatibility constraint reads $z_{B}-20-\alpha_{i} \max \left\{160-2 z_{B}, 0\right\}-$ $\beta_{i} \max \left\{2 z_{B}-160,0\right\} \geq \frac{1}{2}\left(z_{B}-\alpha_{i} \max \left\{140-2 z_{B}, 0\right\}-\beta_{i} \max \left\{2 z_{B}-140,0\right\}\right)+$ $\frac{1}{2}\left(0-70 \alpha_{i}\right)$.Thus, the second-period behavior of the agent is the same as in the case in which first-period effort was high.

Given low first-period effort and a first-period failure, the second-period incentive compatibility constraint is $-20-90 \alpha_{i} \geq \frac{1}{2}\left(0-70 \alpha_{i}\right)$, so that secondperiod effort will always be low.

If $z_{B} \in\{60,70,80\}$ or if $z_{B}=50$ and $\alpha_{i} \leq 1$, the first-period incentive compatibility constraint is $z_{B}-40-\alpha_{i} \max \left\{180-2 z_{B}, 0\right\}-\beta_{i} \max \left\{2 z_{B}-\right.$ $180,0\} \geq \frac{1}{2}\left(z_{B}-20-\alpha_{i} \max \left\{160-2 z_{B}, 0\right\}-\beta_{i} \max \left\{2 z_{B}-160,0\right\}\right)+\frac{1}{4}\left(0-70 \alpha_{i}\right)$. If $z_{B}=50$ and $\alpha_{i}>1$, the constraint is $\frac{1}{2}\left(z_{B}-20-\alpha_{i} \max \left\{160-2 z_{B}, 0\right\}-\right.$ $\left.\beta_{i} \max \left\{2 z_{B}-160,0\right\}\right)+\frac{1}{2}\left(-20-90 \alpha_{i}\right) \geq \frac{1}{4}\left(z_{B}-\alpha_{i} \max \left\{140-2 z_{B}, 0\right\}-\right.$ $\left.\beta_{i} \max \left\{2 z_{B}-140,0\right\}\right)+\frac{1}{2}\left(0-70 \alpha_{i}\right)$. Thus, if $z_{B}=50$, first-period effort will be low. If $z_{B}=60,70$, or 80 , first-period effort is low if $\alpha_{i}>0,2 / 5$, or 4 , respectively, otherwise first-period effort is high.

Principal's behavior. If $z_{A} \in\{25,30,35\}$, then principal $j$ 's expected utility is $\frac{1}{4}\left(140-2 z_{A}-\alpha_{j} \max \left\{4 z_{A}-140,0\right\}-\beta_{j} \max \left\{140-4 z_{A}, 0\right\}\right)+\frac{1}{2}(70-$ $\left.z_{A}-\alpha_{j} \max \left\{2 z_{A}-70,0\right\}-\beta_{j} \max \left\{70-2 z_{A}, 0\right\}\right)$. Suppose the principal believes that $\alpha_{i}=0$. Then her expected utility is $140-2 z_{A}-\alpha_{j} \max \left\{4 z_{A}-\right.$ $180,0\}-\beta_{j} \max \left\{180-4 z_{A}, 0\right\}$ if $z_{A}=40, \frac{1}{2}\left(140-z_{B}-\alpha_{j} \max \left\{2 z_{B}-160,0\right\}-\right.$ $\left.\beta_{j} \max \left\{160-2 z_{B}, 0\right\}\right)+\frac{1}{4}\left(70-70 \beta_{j}\right)$ if $z_{B}=50$, and $140-z_{B}-\alpha_{j} \max \left\{2 z_{B}-\right.$ $180,0\}-\beta_{j} \max \left\{180-2 z_{B}, 0\right\}$ if $z_{B} \in\{60,70,80\}$. Hence, the principal sets $z_{B}=60$ if $\beta_{j} \leq 1 / 2$ and $z_{A}=40$ or $z_{B}=80$ otherwise. In what follows, we consider $\alpha_{i}>0$, so that the principal's expected utility is $\frac{1}{2}(140-80)+$ $\frac{1}{4}\left(70-40-10 \alpha_{j}\right)$ if $z_{A}=40$. Specifically, suppose the principal believes that $0<\alpha_{i} \leq 2 / 5$. Then her expected utility is $\frac{1}{2}\left(140-z_{B}-\alpha_{j} \max \left\{2 z_{B}-\right.\right.$ $\left.160,0\}-\beta_{j} \max \left\{160-2 z_{B}, 0\right\}\right)+\frac{1}{4}\left(70-70 \beta_{j}\right)$ if $z_{B} \in\{50,60\}$ and $140-$ $z_{B}-\alpha_{j} \max \left\{2 z_{B}-180,0\right\}-\beta_{j} \max \left\{180-2 z_{B}, 0\right\}$ if $z_{B} \in\{70,80\}$. Thus, 
she will set $z_{B}=70$ if $\beta_{j} \leq 1 / 2$ and $z_{B}=80$ otherwise. Next, suppose the principal believes that $2 / 5<\alpha_{i} \leq 1$. Then her expected utility is $\frac{1}{2}$ (140$\left.z_{B}-\alpha_{j} \max \left\{2 z_{B}-160,0\right\}-\beta_{j} \max \left\{160-2 z_{B}, 0\right\}\right)+\frac{1}{4}\left(70-70 \beta_{j}\right)$ if $z_{B} \in$ $\{50,60,70\}$ and $140-80-20 \beta_{j}$ if $z_{B}=80$. Hence, the principal sets $z_{B}=50$ if $\beta_{j} \leq 1 / 11$ and $z_{B}=80$ otherwise. Suppose now the principal believes that $1<\alpha_{i} \leq 4$. Then her expected utility is $\frac{1}{4}\left(90-40 \beta_{j}\right)+\frac{1}{2}\left(70-70 \beta_{j}\right)$ if $z_{B}=50$, otherwise her expected utility is as in the previous case, and thus the principal sets $z_{B}=80$. Finally, suppose that the principal believes that $\alpha_{i}>4$. Then her expected utility is $\frac{1}{4}\left(90-40 \beta_{j}\right)+\frac{1}{2}\left(70-70 \beta_{j}\right)$ if $z_{B}=50$ and $\frac{1}{2}\left(140-z_{B}-\alpha_{j} \max \left\{2 z_{B}-160,0\right\}-\beta_{j} \max \left\{160-2 z_{B}, 0\right\}\right)+\frac{1}{4}\left(70-70 \beta_{j}\right)$ if $z_{B} \in\{60,70,80\}$. Hence, in this case the principal sets $z_{B}=60$ if $\beta_{j} \leq 1 / 2$ and $z_{B}=80$ if $1 / 2<\beta_{j} \leq \min \left\{\frac{1}{7} \alpha_{j}+\frac{4}{7}, \frac{5}{7}\right\}$, while otherwise she sets $z_{A}=40$ if $\alpha_{j} \leq 1$, and $z_{A}=35$ if $\alpha_{j}>1$.

\section{Appendix B: Instructions and quiz}

\section{Instructions}

You are participating in an experiment on economic decision-making. All decisions are anonymous, that means that none of the other participants learns the identity of someone having made a certain decision. The payoffs are also anonymous; none of the participants learns how much the others have earned. Please read these instructions carefully.

If you have any questions please look again at the instructions. If you still have questions please give us a signal by raising your hand.

\section{Overview}

In this experiment you and another participant who is chosen by a random generator are assigned to one group. Each group consists of an employer and an employee. At the beginning you are informed whether the role of the employer or the role of the employee has been assigned to you.

All of the payments occurring in the experiment are calculated in a fictitious currency called taler. Your payoff will be converted into euro at the end of the experiment. The exchange rate is 7 taler for one euro.

First, the employer chooses a wage scheme. After that, there are two periods. In each period the employee makes a decision that affects whether the group is in State X or Y. If the group is in State X, the employer receives a return of 70 taler 
from which he will make a previously fixed wage payment to the employee. If the group is in State Y, the employer receives zero taler and the employee does not receive any payment.

\section{Choice of the wage scheme}

The employer can choose between different wage schemes. If he chooses a wage scheme of type A, he pays $z_{A}$ taler to the employee in each period in which State $\mathrm{X}$ is reached.

If the employer chooses a wage scheme of type $\mathrm{B}$, he pays $z_{B}$ taler to the employee once, provided that State $\mathrm{X}$ is reached in both periods.

The employer determines the amount of the payment $\mathrm{Z}$ for each wage scheme bindingly. He can choose from the following alternatives:

\begin{tabular}{|l|l|}
\hline Alternative & Wage scheme $\mathbf{A}$ \\
\hline & (Payment when reaching State $\mathbf{X}$ in the resp. period) \\
\hline 1 & $z_{A}=25$ taler \\
\hline 2 & $z_{A}=30$ taler \\
\hline 3 & $z_{A}=35$ taler \\
\hline 4 & $z_{A}=40$ taler \\
\hline \multicolumn{2}{|l}{} \\
\hline & Wage scheme $\mathbf{B}$ \\
\hline & (Payment when reaching State $\mathbf{X}$ in both periods) \\
\hline 5 & $z_{B}=50$ taler \\
\hline 6 & $z_{B}=60$ taler \\
\hline 7 & $z_{B}=70$ taler \\
\hline 8 & $z_{B}=80$ taler \\
\hline
\end{tabular}

The employee is informed about the alternative the employer has chosen.

\section{First period}

In the first period the employee chooses between two strategies.

- If he chooses Strategy 1, State X or State Y occur with a probability of $50 \%$, respectively. Choosing Strategy 1 does not impose any costs on the employee. 
- If he chooses Strategy 2, State X emerges with a probability of $100 \%$. Choosing Strategy 2 costs the employee 20 taler, which will be subtracted from his payoff.

After the employee has chosen his strategy the software determines (in case of Strategy 1 randomly) if State $\mathrm{X}$ or State $\mathrm{Y}$ is reached in this period. Both players are informed about the result.

\section{Second period}

In the second period the employee chooses again between Strategy 1 and Strategy 2:

- If he chooses Strategy 1, State X or State Y occur with a probability of $50 \%$, respectively. Choosing Strategy 1 does not impose any costs on the employee.

- If he chooses Strategy 2, State X emerges with a probability of $100 \%$. Choosing Strategy 2 costs the employee 20 taler, which will be subtracted from his payoff.

After the employee has chosen his strategy the software determines (in case of Strategy 1 randomly) if State X or State Y is reached in this period. Both players are informed about the result and about the total payoffs in the experiment.

\section{Overview of possible results and payments:}

\begin{tabular}{|c|c|c|c|c|}
\hline \multicolumn{2}{|c|}{ Result } & \multirow{2}{*}{$\begin{array}{l}\text { Employer } \\
\text { Return }\end{array}$} & \multicolumn{2}{|c|}{ Employee } \\
\hline Period 1 & Period 2 & & Wage scheme A & Wage scheme B \\
\hline State Y & State Y & 0 & 0 & 0 \\
\hline State X & State Y & 70 & $z_{A}$ & 0 \\
\hline State Y & State X & 70 & $z_{A}$ & 0 \\
\hline State X & State X & 140 & $2 z_{A}$ & $z_{B}$ \\
\hline
\end{tabular}

Please note that the employer's payoff is calculated from the obtained returns minus the employee's wage. The employee's payoff is calculated from his wage minus the respective costs for choosing Strategy 2 if it was chosen. Additionally, you receive a show-up-fee of 3 euro.

Finally, we ask you to carefully answer a short questionnaire appearing on the screen at the end of the experiment.

When all players have finished this questionnaire they will receive their payoffs. Please stay seated at the end of the experiment until we call your cabin number.

\section{Good luck!}


Quiz to check the understanding of the subjects before the experiment started

- What is the return of the employer at the end of one period if the group is in state $\mathrm{X}$ ?

- What is the return of the employer at the end of one period if the group is in state $\mathrm{Y}$ ?

- If the employer selects wage scheme A, the employee receives $z_{A}$ if

- State X has been reached in the respective period.

- State X has been reached in both periods.

- If the employer selects wage scheme $\mathrm{B}$, the employee receives $z_{B}$ if

- State X has been reached in the respective period.

- State X has been reached in both periods.

- State $\mathrm{X}$ is reached with a probability of $50 \%$ if

- Strategy 1 is chosen.

- Strategy 2 is chosen.

- State $\mathrm{X}$ is reached with a probability of $100 \%$ if

- Strategy 1 is chosen.

- Strategy 2 is chosen.

\section{Acknowledgements}

Petra Nieken gratefully acknowledges financial support from the Deutsche Forschungsgemeinschaft (DFG), grant SFB/TR 15. Patrick Schmitz gratefully acknowledges financial support from the Deutsche Forschungsgemeinschaft (DFG), grant FOR 1371. 


\section{References}

Akerlof, G.A., Katz, L.F., 1989. Workers' trust funds and the logic of wage profiles. Quart. J. Econ. 104, 525-536.

Bellemare, C., Kröger, S., Van Soest, A., 2008. Measuring inequity aversion in a heterogeneous population using experimental decisions and subjective probabilities. Econometrica 76, 815-839.

Blanco, M., Engelmann, D., Normann, H.T., 2011. A within-subject analysis of other-regarding preferences. Games Econ. Behav. 72, 321-338.

Bolton, P., Dewatripont, M., 2005. Contract Theory. Cambridge, MA: MIT Press.

Chiappori, P., Macho, I., Rey, P., Salanié, B., 1994. Repeated moral hazard: The role of memory, commitment, and the access to credit markets. Europ. Econ. Rev. 38, 1527-1553.

Dannenberg, A., Riechmann, T., Sturm, B., Vogt, C., 2007. Inequity aversion and individual behavior in public good games: An experimental investigation. ZEW Discussion Paper No. 07-034.

De Bruyn, A., Bolton, G.E., 2008. Estimating the influence of fairness on bargaining behavior. Manag. Sci. 54, 1774-1791.

Fehr, E., Schmidt, K.M., 1999. A theory of fairness, competition, and cooperation. Quart. J. Econ. 114, 817-868.

Fehr, E., Schmidt, K.M., 2006. The economics of fairness, reciprocity and altruism - experimental evidence and new theories. in: Kolm, S.C., Ythier, J.M. (Eds.), Handbook on the Economics of Giving, Reciprocity and Altruism 1. North Holland, Amsterdam, pp. 615-691.

Fischbacher, U., 2007. z-Tree - Zurich toolbox for readymake economic experiments. Exper. Econ. 10, 171-178.

Fudenberg, D., Holmström, B., Milgrom, P., 1990. Short-term contracts and long-term agency relationships. J. Econ. Theory 51, 1-31.

Goeree, J.K., Holt, C.A., 2000. Asymmetric inequality aversion and noisy behavior in alternating-offer bargaining games. Europ. Econ. Rev. 44, 1079-1089. 
Greiner, B., 2004. An online recruitment system for economic experiments, in: Kremer, K., Macho, V. (Eds.). Forschung und wissenschaftliches Rechnen, GWDG Bericht 63, Ges. für wiss. Datenverarbeitung, Göttingen, pp. 79-93.

Holt, C.A., Laury, S.K., 2002. Risk aversion and incentive effects. Amer. Econ. Rev. 92, 1644-1655.

Huck, S., Seltzer, A.J., Wallace, B., 2011. Deferred compensation in multi-period labor contracts: An experimental test of Lazear's model. Amer. Econ. Rev. $101,819-843$.

Innes, R.D., 1990. Limited liability and incentive contracting with ex-ante action choices. J. Econ. Theory 52, 45-67.

Laffont, J.-J., Martimort, D., 2002. The Theory of Incentives: The PrincipalAgent Model,. Princeton, N.J.: Princeton University Press.

Lazear, E.P., 1979. Why is there mandatory retirement? J. Political Econ. 87, $1261-1284$.

Lazear, E.P., 1981. Agency, earnings profiles, productivity, and hours restrictions. Amer. Econ. Rev. 71, 606-620.

Malcomson, J.M., Spinnewyn, F., 1988. The multiperiod principal-agent problem. Rev. Econ. Stud. 55, 391-407.

Maskin, E., 1999. Nash equilibrium and welfare optimality. Rev. Econ. Stud. $66,23-38$.

Maskin, E., Sjöström, T., 2002. Implementation theory, in: Arrow, K.J., Sen, A.K., Suzumura, K. (Eds.), Handbook of Social Choice and Welfare 1. North Holland, Amsterdam, pp. 237-288.

McKelvey, R.D., Palfrey, T.R. 1995. Quantal response equilibria in normal form games. Games Econ. Behav. 10, 6-38.

McKelvey, R.D., Palfrey, T.R. 1998 Quantal response equilibria in extensive form games. Exper. Econ. 1, 9-41.

Ohlendorf, S., Schmitz, P.W., 2012. Repeated moral hazard and contracts with memory: The case of risk-neutrality. Internat. Econ. Rev., forthcoming. 
Pitchford, R., 1998. Moral hazard and limited liability: The real effects of contract bargaining. Econ. Letters 61, 251-259.

Rey, P., Salanié, B., 1990. Long-term, short-term and renegotiation: On the value of commitment in contracting. Econometrica 58, 597-619.

Rogers, B.W., Palfrey, T.R., Camerer, C.F., 2009. Heterogeneous quantal response equilibrium and cognitive hierarchies. J. Econ. Theory 144, 14401467.

Rogerson, W.P., 1985. Repeated moral hazard. Econometrica 53, 69-76.

Schmitz, P.W., 2005. Allocating control in agency problems with limited liability and sequential hidden actions. Rand J. Econ. 36, 318-336. 